\title{
IMPACT OF CUO CONTENT ON THE DIELECTRIC PROPERTIES OF ZINC SODIUM PHOSPHATE GLASSES CONTAINING $\mathrm{Al}_{2} \mathrm{O}_{3}$
}

\author{
H. A. Elshaikh, Y. H. Elbashar, Ali M. Ibrahimand A. G. Mostafa*
}

Physics Department, Faculty of Science, Aswan University, Aswan, Egypt

"Physics Department, Faculty of Science, Al-Azhar University, (11884) Nasr City, Cairo-Egypt

\begin{abstract}
Dielectric properties of some copper sodium phosphate glasses containing alumina have been studied in the frequency range from 1.05 to $100 \mathrm{kHz}$ under vacuum $\left(10^{-5}\right.$ torr $)$. The dielectric parameters e.g. dielectric constant, dielectric loss, dielectric loss tangent and ac conductivity, have been calculated. The frequency dependence of the dielectric constant indicates the presence of dipole electric polarization due to linking of one $\mathrm{Cu}^{2+}$ ion with two non-bridging oxygens and ionic polarization due to the accumulation of sodium ions at the interfaces. The frequency dependence of the dielectric loss indicates that the conduction is a dominant contribution to the energy loss. The ac conductivity measurements exhibit the coexistence of electronic (due to the electron hopping from $\mathrm{Cu}^{+}$to $\mathrm{Cu}^{2+}$ ions) and ionic (due to the mobility of sodium ions).
\end{abstract}

Keywords: Dielectric glass, Copper phosphate glass, Glass technology, Glass containing two transition ions, Alumino-phosphate glass.

\section{INTRODUCTION}

Oxide glasses are distinguished by several advantages, e.g. composition diversity, good chemical durability (especially when some metallic ions are introduced into their networks), and low-cost starting materials as well as their various applications [1]. On the other hand, phosphate glasses have lower glass transition temperature, higher thermal expansion coefficient and higher transmission in the UV region compared with silicate and borate glasses [2]. It is known that, phosphate glasses represent a dielectric energy-storage material, and therefore, they are useful for fabricating high energy density devices [3].The addition of transition metal oxides, such as $\mathrm{Fe}_{2} \mathrm{O}_{3}$, to phosphate glasses makes them more chemical resistive due to the replacing of the easily hydrated $\mathrm{P}-\mathrm{O}-\mathrm{P}$ bonds by the stronger Fe-O-P ones [4]. The effect of $\mathrm{ZnO}$ concentration on the dielectric properties of magnesium zinc phosphate glasses has been investigated [5], where the obtained results showed that the dielectric constant and dielectric strength rise with increasing $\mathrm{ZnO}$ content due to the increase of the dipole density associated to $\mathrm{Zn}^{2+}$ ions. It was found also that the excessive zinc ions tend to occupy the interstitial sites instead of substitution sites, while in sodium phosphate glasses, the addition of $\mathrm{CuO}$ improves also the chemical durability of the glass networks [6].

However, the present work aims to investigate the dielectric properties of some phosphate glasses having the composition, $45 \mathrm{P}_{2} \mathrm{O}_{5}-32 \mathrm{ZnO}-(20-\mathrm{x}) \mathrm{Na}_{2} \mathrm{CO}_{3}-\mathrm{xCuO}-3 \mathrm{Al}_{2} \mathrm{O}_{3}$;

(where $\mathrm{x}=0,1,2,3,4$ or 5 . In addition, the effect of introducing $\mathrm{CuO}$ into the glass networks on the dielectric parameters will be also investigated.

\section{EXPERIMENTAL}

Some phosphate glasses of the composition $45 \mathrm{P}_{2} \mathrm{O}_{5}-32 \mathrm{ZnO}-(20-\mathrm{x}) \mathrm{Na}_{2} \mathrm{O}-\mathrm{xCuO}-3 \mathrm{Al}_{2} \mathrm{O}_{3}$; $\mathrm{x}=$ $0,1,2,3,4$ and 5 , were prepared using the conventional melt quenching technique.

$\left(\mathrm{NH}_{4}\right)_{2} \mathrm{HPO}_{4}, \mathrm{ZnO}, \mathrm{Na}_{2} \mathrm{CO} 3, \mathrm{CuO}$ and $\mathrm{Al}_{2} \mathrm{O}_{3}$ are used as starting materials. Each composition was carefully weighted and then mixed using a porcelain mortar. The mixture was then melted in porcelain crucible placed in a muffle furnace at $1000{ }^{\circ} \mathrm{C}$ for one hour. Then, the melt was casted on a stain-less steel molds placed in another muffle furnace at $300{ }^{\circ} \mathrm{C}$. The casted 
H. A. ELSHAIKH, et al.

melts were left to annealed for one hour and the .furnace was turned off and left to cool to RT

The XRD analysis has been carried out to confirm the amorphous nature of these glasses [7]. Five pieces (one of each sample) were cut and finely polished to become like-slabs with flat faces to be suitable for the dielectric measurements. For such a slab, a thin layer of silver paste was coated on the two opposite surfaces to serve as electrodes and two metal electrodes were contacted to the faces of each slab after the silver paint has dried. The ohmic contact was confirmed using the $\mathrm{I}-\mathrm{V}$ characteristic measurements. The dielectric measurements were carried out in an evacuated medium whereas such a sample under investigation was mounted on the finger of the holder inside the OPTISTAT-DN2 (OXFORD NANOSCIENCE CORPORATION) that was evacuated to about $10^{-5}$ torr using turbo pumping station model Pfeiffer HiCube 80 Eco. The dielectric measurements were carried out using HIOKI LCR HiTESTER Model 3532-50 with a frequency range from 1.05 to $100 \mathrm{kHz}$ ( \pm $0.005 \%)$.

\section{RESULTS and DISCUSSION:}

\subsection{The Dielectric Properties:}

\subsubsection{Frequency Dependences Dielectric Parameters:}

The dielectric measurements were carried out in a frequency range extending from 1.05 to $100 \mathrm{kHz}$. With the aid of these measurements, the dielectric parameters e.g. the dielectric constant $\left(\varepsilon^{\prime}\right)$, the dielectric loss $\left(\varepsilon^{\prime \prime}\right)$, the dissipation factor $(\tan \delta)$ and the alternatingcurrent conductivity $\left(\sigma_{\mathrm{ac}}\right)$ were evaluated for all composites under investigation. The frequency dependence of the dielectric parameters are illustrated in Figures (1, 2, 3 and 4 respectively). The complex dielectric constant of a material is generally formulated as two parts: $\varepsilon=\varepsilon^{\prime}+\mathrm{j} \varepsilon^{\prime \prime}$; where $\varepsilon^{\prime}$ is the real part of dielectric constant, that is a measure of the energy stored from the applied electric field in the material and identifies the strength of alignment of dipoles in a dielectric medium. While $\varepsilon^{\prime \prime}$ is the dielectric loss or the imaginary part of dielectric constant, that is the energy dissipated in the dielectric associated with the frictional dampening, which prevents the displacement of bound charge from keeping in phase with the field variations. Both the dielectric constant $\left(\varepsilon^{\prime}\right)$ and dielectric loss $\left(\varepsilon^{\prime \prime}\right)$ can be evaluated for the samples under investigation by measuring the equivalent parallel capacitance $\left(C_{p}\right)$ and the equivalent parallel resistance $\left(R_{p}\right)$ as well as the geometrical capacitance of vacuum through the same dimensions of a sample under investigation $\left(\mathrm{C}_{0}\right)$, by applying $\mathrm{g}$ the following equations [8],:

$$
\varepsilon^{\prime}=\mathrm{C}_{\mathrm{p}} / \mathrm{C}_{0} \quad \Rightarrow \quad \varepsilon^{\prime}=\left(\frac{\mathrm{Cd}}{\varepsilon_{0} \mathrm{~A}}\right)
$$

$$
\varepsilon^{\prime \prime}=\left(\frac{\varepsilon^{\prime}}{\omega \mathrm{C}_{\mathrm{p}} \mathrm{R}_{\mathrm{p}}}\right)
$$

where $\mathrm{C}$ is the capacitance of the sample medium in Farad, $d$ is the thickness in meter, $\mathrm{A}$ is the area in square meter, and $\varepsilon_{0}$ is the absolute permittivity in the free space having a value of $8.854 \times 10^{-12} \mathrm{Fm}^{-1}$. Based on the values of the real and imaginary parts of dielectric constant, the dissipation factor or loss factor tangent (tan $\delta$ ) means the phase difference due to the loss of energy within the material and can be expressed as [9],

$$
\tan \delta=\varepsilon^{\prime \prime} / \varepsilon^{\prime}
$$

The dielectric constant indicates an electrical polarization which can be occurred due to the presence of a dielectric material in an alternating-current field. There are four electrical polarization mechanisms specified as electronic, ionic (or atomic), dipolar (or orientational) and space charge polarization $[10,11]$ and they can be discussed in brief as follows,

i) Electronic polarization $\left(\mathrm{P}_{\mathrm{e}}\right)$ that arises due to the displacement of the valence electrons relative to the positive nucleus and occur at frequencies up to $10^{16} \mathrm{~Hz}$. 
IMPACT OF CuO CONTENT ON THE DIELECTRIC PROPERTIES ...

ii) Ionic polarization $\left(\mathrm{P}_{\mathrm{i}}\right)$ that arises due to the displacement of negative and positive ions with respect to each other. In this type, the ions cannot be polarized rapidly since they are heavier than electrons and therefore, ionic polarization occurs approximately at $10^{13} \mathrm{~Hz}$.

iii) Dipolar polarization $\left(\mathrm{P}_{\mathrm{d}}\right)$ that arises due to the permanent electric dipole moments of molecules by which they change their orientation into the direction of the applied electric field. Dipolar polarization occurs at frequencies up to about $10^{10} \mathrm{~Hz}$.

iv) The space charge polarization $\left(\mathrm{P}_{\mathrm{s}}\right)$ that arises due to the mobile charge carriers impeded at the interfaces. Space charge polarization typically occurs at frequencies between 1 and $10^{3} \mathrm{~Hz}$.

The dielectric constant $\left(\varepsilon^{\prime}\right)$ determines the maximum energy that can be stored in the material, while the loss factor $\left(\varepsilon{ }^{\prime \prime}\right)$ evaluates the absorption of electrical energy by a dielectric material that subjected to an alternating electromagnetic field. Furthermore, the dissipation factor $\left(\tan \delta=\varepsilon^{\prime \prime} / \varepsilon^{\prime}\right)$ determines how a material can absorb the electromagnetic field [10-13]. The values of the alternating current conductivity $\left(\sigma_{\text {ac }}\right.$ ) for all samples under investigation were calculated using the following relation [14],

$$
\sigma_{\text {ac }}(f)=2 \pi f \varepsilon_{\mathrm{n}} \varepsilon^{\prime} \tan \delta
$$

Where $f$ is the frequency of the applied ac electric field in $\mathrm{Hz}$ and $\tan \delta$ is the dissipation factor that describes the phase difference between the current and voltage with respect to the applied ac electric field.

Figure (1) illustrates the frequency dependence of the real part of the dielectric for all the investigated samples. It is observed that the real part of dielectric exhibits a noticeable decrease with increasing the applied frequency for all samples. The behavior of the real part (dielectric constant) could be interpreted with respect to the frequency intervals. At the low frequency region $(1.05-8.12 \mathrm{kHz})$, the dielectric constant decreases sharply with increasing frequency indicating a strong dependence of this parameter on the frequency at the low frequency region. In the high frequency region $(8.12-100 \mathrm{kHz})$, this parameter starts to decrease slightly with increasing frequency. Since the dielectric properties arise due to ionic diffusions within a conducting material when an electric field is applied and the charge carriers in a glass cannot move freely throughout the glass matrix but they can be displaced and polarized as a response to the applied alternating field. Therefore higher values of the real part of the dielectric constant at low frequencies may be due to the presence of large capacitance at the electrode-electrolyte interface, which apparently reduces the ac current [15]. But the lower values of the dielectric constant $\left(\varepsilon^{\prime}\right)$ at high frequencies indicates the importance of these glasses in the construction of photonic and Non-Linear Optical (NLO) devices [16]. Consequently, the dielectric constant ( $\varepsilon$ ') profile at low frequencies exhibits a high dispersion because the ions are not in a position to diffuse themselves along with the electric field direction and as a result, charges accumulate in the space charge region at the electrodeelectrolyte interface due to the net polarization effect. At higher frequencies, the periodic revers of the electric field at the interface occurs so fast that no excess ions can accumulate in the electric field direction [17] and hence, the dielectric constant is lowered by weakening the ion-ion interaction of the dipoles and as hence their contribution to the polarization would be reduced gradually.

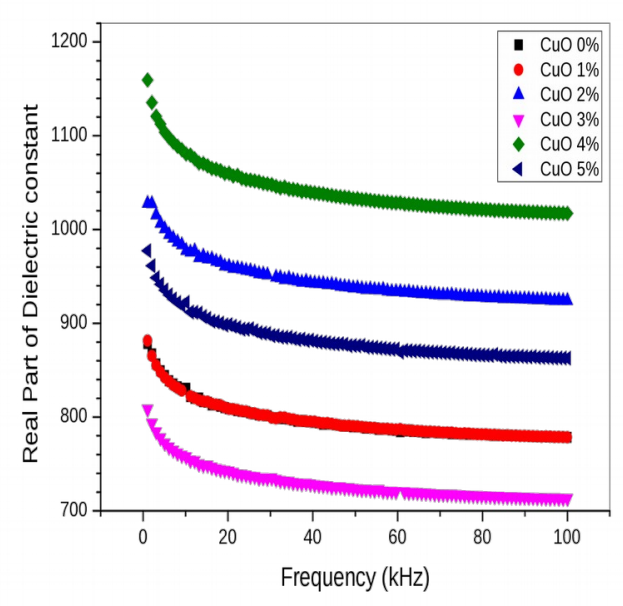

Figure 1: The frequency dependence of dielectric constant $\left(\varepsilon^{\prime}\right)$ for all samples under investigation; note that there is a coincidence between the curves due to the samples containing $0 \%$ and $1 \% \mathrm{CuO}$. 
Changes in dielectric constant $\left(\varepsilon^{\prime}\right)$ and dielectric loss $\left(\varepsilon^{\prime \prime}\right)$ with frequency exhibit effects of the dielectric relaxation (see Figures $1 \& 2)$. Such effects of dielectric relaxation are observed when the metallic ions are present in their divalent states [18]. These effects are observed for all samples under investigation, due to the formation of dipoles from the divalent copper ions together with a pair of cationic vacancies. The considerable decrease in the dielectric constant and loss factor at low frequencies observed for these glasses can be ascribed to the defects produced in the glass matrix which contribute to the space charge polarization that comes from the mobility of ions and defects in the glass networks [19]. Furthermore, the decrease in $\varepsilon^{\prime}$ and $\varepsilon^{\prime \prime}$ with increasing frequency could be explained according to the fact that, as the frequency is raised the interfacial dipoles have less time to orient themselves in the direction of the alternating field [20-22]. Both the dielectric loss $(\varepsilon ")$ and dissipation factor $(\tan \delta$ ) exhibit high dependency on frequency in the shorter intervals, at the low working frequency region than that noticed for the real part of dielectric constant. These parameters undergo sharp decrease with increasing frequency at the low frequency interval $(1.05-8.12 \mathrm{kHz})$ for all samples under investigation. Formally, typical behaviors of dielectric loss $\left(\varepsilon{ }^{\prime \prime}\right)$ and the dissipation factor for all samples are obviously illustrated in Figures ( 2 \& 3) respectively. The noticed higher values of $\tan \delta$ at the low frequency range for all samples may be due to the presence of some defects such as oxygen vacancies that plays an important role in the conductivity [23]. The alternating-current conductivity is known to be related to the dissipation factor according to the equation [24],

$$
\tan \delta \propto\left(\sigma_{a c} / \omega\right)
$$

The increase in the conductivity is smaller than that of frequency, and hence $\tan \delta$ decreases with increasing frequency. It is evident from Figure (3) that the dielectric loss tangent decreases with increasing frequency due to mobility of the conducting species. The higher the mobility of the conducting species, the higher would be the dielectric loss tangent [25].

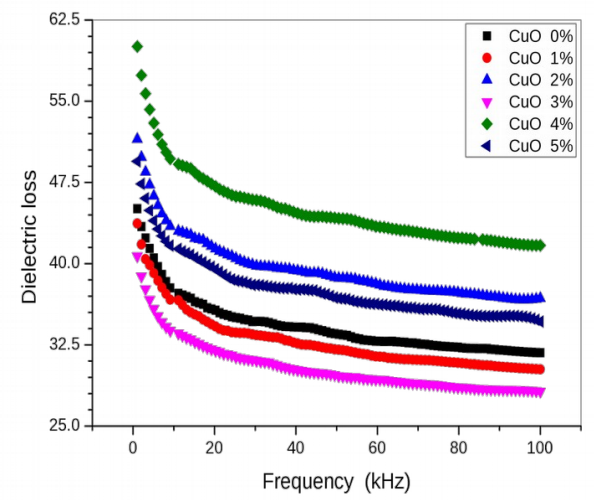

Figure 2: The frequency dependence of dielectric loss $(\varepsilon ')$ for the investigated samples.

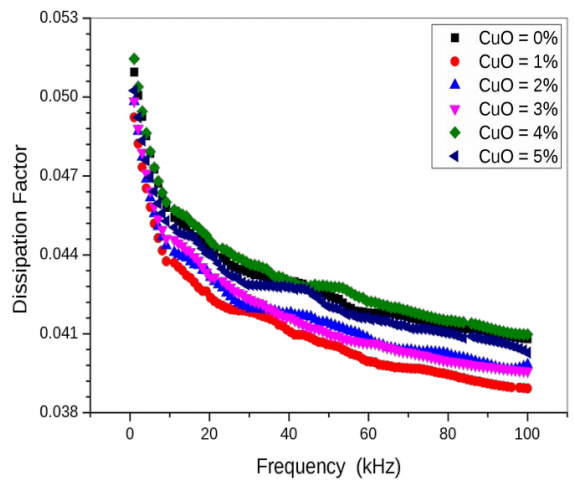

Figure 3: Frequency dependence of the dissipation factor for all the studied glasses.

Figure (4) illustrates the frequency dependence of the alternating-current conductivity $\left(\sigma_{\mathrm{ac}}\right)$ in the frequency range extending from 1.05 to $100 \mathrm{kHz}$ and for all samples under investigation. It is clear from this figure that all samples exhibit approximately gradual linear increase for the whole working frequency range. Nearly the same behavior is also observed for sodium phosphate glass [26].

The measured total conductivity $\left(\sigma_{\mathrm{T}}\right)$ can be considered as a summation of the dc and ac conductivities $\left(\sigma_{\mathrm{dc}}+\sigma_{\mathrm{ac}}\right)$. The $\mathrm{dc}$ part is independent of frequency and is dominant at lower frequencies and it appears as a flat dc plateau at the low frequency region. Such plateau can be considered as an indicative for the domination of dc conductivity and it is 
IMPACT OF CuO CONTENT ON THE DIELECTRIC PROPERTIES ...

observed at high temperature but unobservable at room temperature [26]. On the other hand, the ac conductivity is approximately independent of frequency at low frequencies but it is frequency dependent at the high frequency region. The total conductivity can follow the power relation [16]

$$
\begin{aligned}
& \sigma_{T}=\sigma_{d c}+A \omega^{s} \\
& \sigma_{a c}=A \omega^{s}
\end{aligned}
$$

where $\mathrm{A}$ is a weakly temperature dependent factor and $\mathrm{s}$ is the exponent factor (usually less than or equal to unity). At the high frequency region, $A \omega^{\mathrm{s}}>>\sigma_{\mathrm{dc}}$, the total conductivity is equal to the ac conductivity [27].

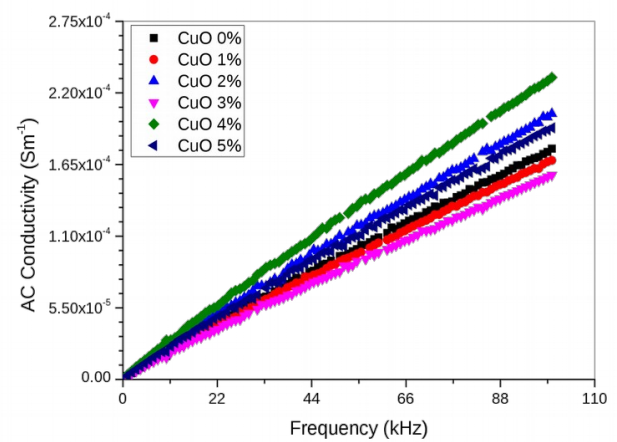

Figure 4:The frequency dependence of the alternatingcurrent conductivity for the investigated glass samples.

Equation (7) is referred as a universal dynamic pattern of the ac electrical behavior of conducting solids and liquids as proposed by Jonscher [28] based on the exponent $s$ that lies in the range, $0<\mathrm{s}<1$. It has been used mostly to characterize the electrical conduction mechanism in disorder ionic glasses, amorphous semiconductors and ionic conductors [29-31]. This power law is related to the dynamics of hopping transport between states in the forbidden gap [32]. The interpretation of the exponent factor (s) usually involves the analysis of the temperature dependence of s (s versus $T$ ) and composition dependence of $\mathrm{s}$ ( $s$ versusx) that makes it possible to find the relevance of the hopping mechanism in terms of pair approximation [30]. Based on the aforementioned power law, the quantity $\ln _{\text {ac }}$ was then plotted as a function of ln $\omega$, that depicted in Figure (5). Using this figure, the values of the exponent $s$ for all samples under investigation were evaluated by calculating the slopes of the resulted straight lines. In the current work, the estimated values of the exponent s, for the all glasses were found to be about 0.92 that is less than unity which represents the ion transport characterized by the forward-backward hopping process [33]. The linear behavior of the $\ln \left(\sigma_{a c}\right)-\ln (\omega)$ relation indicates the presence of small polaron conduction mechanism between copper ions in the investigated glasses [34].

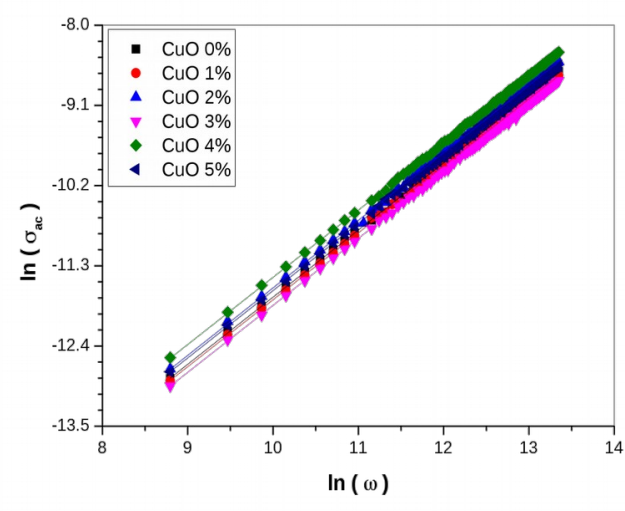

Figure 5: The variation of $\ln \left(\sigma_{a c}\right)$ with $\ln (\omega)$.

\subsubsection{Effect of Copper Ions Content on the Dielectric Parameters:}

The dependence of the real and imaginary parts of dielectric are depicted in Figures (6.a \& 6.b) respectively. According to Figures ( 2 and 3 ), it is seen that, both the real and imaginary parts of the dielectric decreased with increasing frequency from 1.05 to $100 \mathrm{kHz}$. The obtained maximum and minimum values of the dielectric parameters $\left(\varepsilon^{\prime}, \varepsilon^{\prime \prime}, \tan \delta\right.$ and $\left.\sigma_{\text {ac }}\right)$ are presented in Table (1) and their variations can be shown in Figures (6, a \& b). According to this figure, it is observed that $\varepsilon$ exhibits a nonsystematic behavior with the variation of $\mathrm{CuO}$ content. However, this trend can be considered as a fluctuated increase of the dielectric constant with rising $\mathrm{CuO}$ concentration. In order to interpret this behavior, it have to recall the dependence of dielectric constant on $\mathrm{CuO}$ content for glasses having lower amounts of $\mathrm{Al}_{2} \mathrm{O}_{3}$, reported in references [35-37]. 
Table 1: The max. and min. values of the dielectric constant, dielectric loss and ac conductivity

\begin{tabular}{|c|c|c|c|c|c|c|}
\hline \multirow{2}{*}{$\begin{array}{c}\text { CuO } \\
\%\end{array}$} & \multicolumn{2}{|c|}{$\begin{array}{c}\text { dielectric } \\
\text { constant } \varepsilon^{\prime}\end{array}$} & \multicolumn{2}{c|}{$\begin{array}{c}\text { dielectric } \\
\text { loss } \varepsilon^{\prime \prime}\end{array}$} & \multicolumn{2}{c|}{$\begin{array}{c}\text { AC } \\
\text { conductivity }\end{array}$} \\
\cline { 2 - 7 } & Max & Min & Max & Min & Min & Max \\
\hline 0 & 878.46 & 778.39 & 45.08 & 31.87 & $2.64 \mathrm{E}-06$ & $1.77 \mathrm{E}-04$ \\
\hline 1 & 881.42 & 778.37 & 43.71 & 30.25 & $2.56 \mathrm{E}-06$ & $1.68 \mathrm{E}-04$ \\
\hline 2 & 1027.89 & 924.17 & 51.50 & 36.71 & $3.01 \mathrm{E}-06$ & $2.04 \mathrm{E}-04$ \\
\hline 3 & 808.39 & 713.17 & 40.70 & 28.21 & $2.38 \mathrm{E}-06$ & $1.57 \mathrm{E}-04$ \\
\hline 4 & 1159.46 & 1017.19 & 60.05 & 41.69 & $3.51 \mathrm{E}-06$ & $2.32 \mathrm{E}-04$ \\
\hline 5 & 977.38 & 862.73 & 49.44 & 34.75 & $2.89 \mathrm{E}-06$ & $1.93 \mathrm{E}-04$ \\
\hline
\end{tabular}

The dielectric properties of phosphate glasses with the composition $45 \mathrm{P}_{2} \mathrm{O}_{5}-35 \mathrm{ZnO}-$ $(20-\mathrm{x}) \mathrm{Na}_{2} \mathrm{O}-\mathrm{xCuO}$, where $\mathrm{x}=0,1,2,3,4$ or 5 have been studied [35], where the dielectric constant was found to increase with increasing $\mathrm{CuO}$ content due to the increase of the dipole density. Since the dipoles are formed as a result of linking one $\mathrm{Cu}^{2+}$ ion with two non-bridging oxygens. But the space charge polarization, which comes from the presence of the mobile $\mathrm{Na}^{+}$ions is neglected in these glasses.

The addition of one or two mol\% $\mathrm{Al}_{2} \mathrm{O}_{3}$, replacing $\mathrm{ZnO}$, into the composition of the above glasses causes an increase in the molar volume and hence in the mobility of the present sodium ions [36 \& 37]. Therefore, the charge polarization becomes of high effect especially for glasses having low $\mathrm{CuO}$ content. The dominance of the charge polarization extended to glass having $2 \mathrm{~mol} . \% \mathrm{CuO}$, when entering only $1 \mathrm{~mol} \% \mathrm{Al}_{2} \mathrm{O}_{3}$ [36], while it extends to glass having $3 \mathrm{~mol} \% \mathrm{CuO}$ for glasses containing $2 \mathrm{~mol} \% \mathrm{Al}_{2} \mathrm{O}_{3}$ [37].

In the current investigation, the fluctuated increase of the dielectric constant with increasing $\mathrm{CuO}$ may be due to the dominance of charge polarization, which leads to reducing the dielectric constant in the presence of dipole polarization which associated with $\mathrm{Cu}^{2+}$ ions. Furthermore, it can be suggested that this behavior may arise due to the appearance of another parameter which is the presence of $\mathrm{Cu}^{+}$ ions. Babu et al. [38] reported that a part of copper ions are exist in $\mathrm{Cu}^{+}$state in addition to $\mathrm{Cu}^{2+}$ state especially in glasses containing low
$\mathrm{Al}_{2} \mathrm{O}_{3}$ concentration. However, the addition of more than $3 \mathrm{~mol} \% \mathrm{Al}_{2} \mathrm{O}_{3}$ into glasses containing $\mathrm{CuO}$ cause some $\mathrm{Cu}^{2+}$ to transfer into $\mathrm{Cu}^{+}$ions. These $\mathrm{Cu}^{+}$ions participate in the network former positions as $\mathrm{CuO}_{4}$ structural units which increasing the rigidity of the glass network [38]. Such cross-links can reduce the degree of disorder in the glass network and decrease the space charge polarization [39]. It can be supposed that $\mathrm{Cu}^{+}$ions play two main roles:

a) They may deactivate the effect of sodium ions on decreasing the dielectric constant by reducing the pathways suitable for the migration of the free sodium ions that build up the space charges.

b) They can diminish the role of $\mathrm{CuO}$ in the evolution of the dielectric constant due to the formation of the cross-linking tetrahedral $\mathrm{CuO}_{4}$ units.

Therefore, the addition of $\mathrm{CuO}$ content into those glasses containing $3 \mathrm{~mol} \% \mathrm{Al}_{2} \mathrm{O}_{3}$ is associated with an increase in the number of $\mathrm{Cu}^{+}$ions which act as network former leading to a slight and fluctuated increase in the dielectric constant with increasing $\mathrm{CuO}$ content.

The variation of the dielectric loss with $\mathrm{CuO}$ concentration of the investigated glasses exhibits a similar behavior as that of the dielectric constant. Such variation can be attributed to the net polarization and the conduction process [40]. Since the variation of the dielectric loss for all the studied glasses show no loss peaks over the whole measuring frequency range. This indicates that the conduction loss is the dominant contribution to the dielectric loss [41].

Figures (7.a \& b) show the influence of $\mathrm{CuO}$ content on the ac conductivity of the investigated glasses at two constant frequencies (1.05 and 100) kHz respectively. The maximum and minimum values of the measured ac conductivity are also presented in Table (1). It is observed that the ac conductivity exhibits a slight and fluctuated increase as $\mathrm{CuO}$ content was increased. There are two contributions to 
IMPACT OF CuO CONTENT ON THE DIELECTRIC PROPERTIES ...

the conductivity, electronic and ionic conductivities, where the electronic conductivity comes from polaron hopping mechanism while ionic conductivity is related to the existence of mobile ions. Electronic conduction is dominant contribution in glasses containing transition metal oxides due to the ability of their ions to exist in more than one valence state [42] and conduction occurs by the electron transfer from ions in a lower valence state to those in a higher valence state. Hence, glasses containing transition metal ions possess high tendency to form small polarons and conduction may occur by hopping of small polarons between ions in the low and high valence states [43]. Consequently, electronic conduction in the studied glasses arises from the electron hopping between $\mathrm{Cu}^{+}$and $\mathrm{Cu}^{2+}$ ions, and the polaron hoping is strongly dependent on the $\left[\mathrm{Cu}^{2+} / \mathrm{Cu}_{\text {tot }}\right]$ ratio and the average
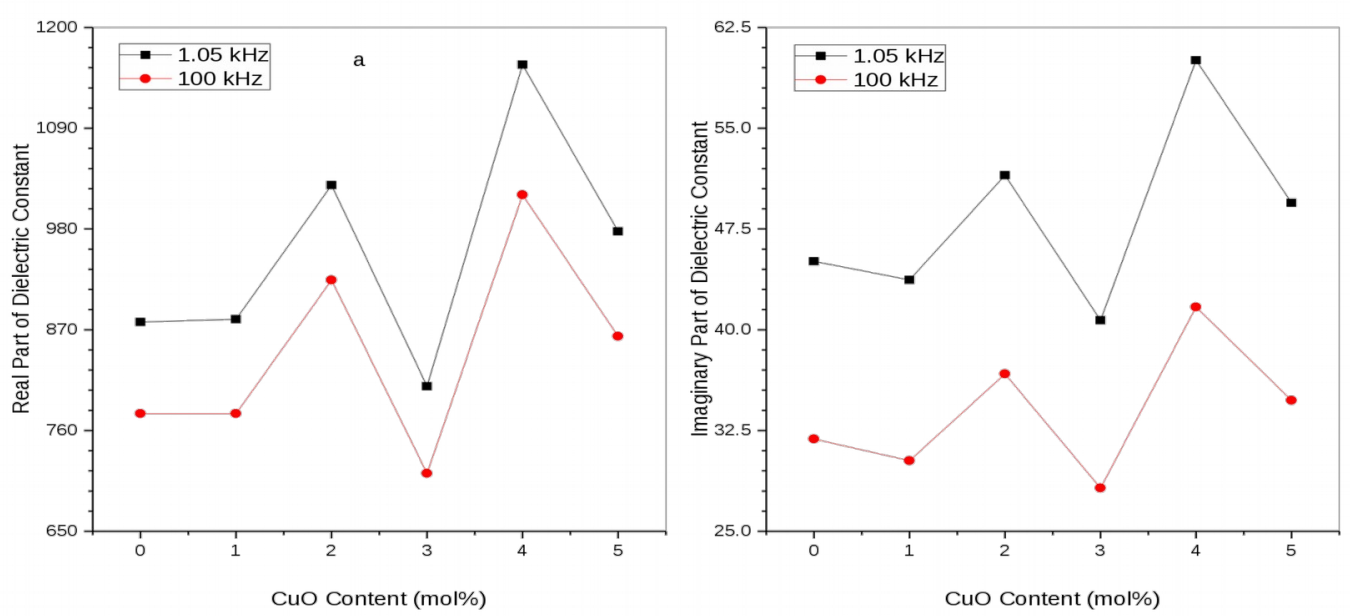

Figure 6: The influence of $\mathrm{CuO}$ addition on the real $\varepsilon^{\prime}(\mathrm{a})$ and imaginary $\varepsilon^{\prime \prime}(\mathrm{b})$ parts of dielectric constant.
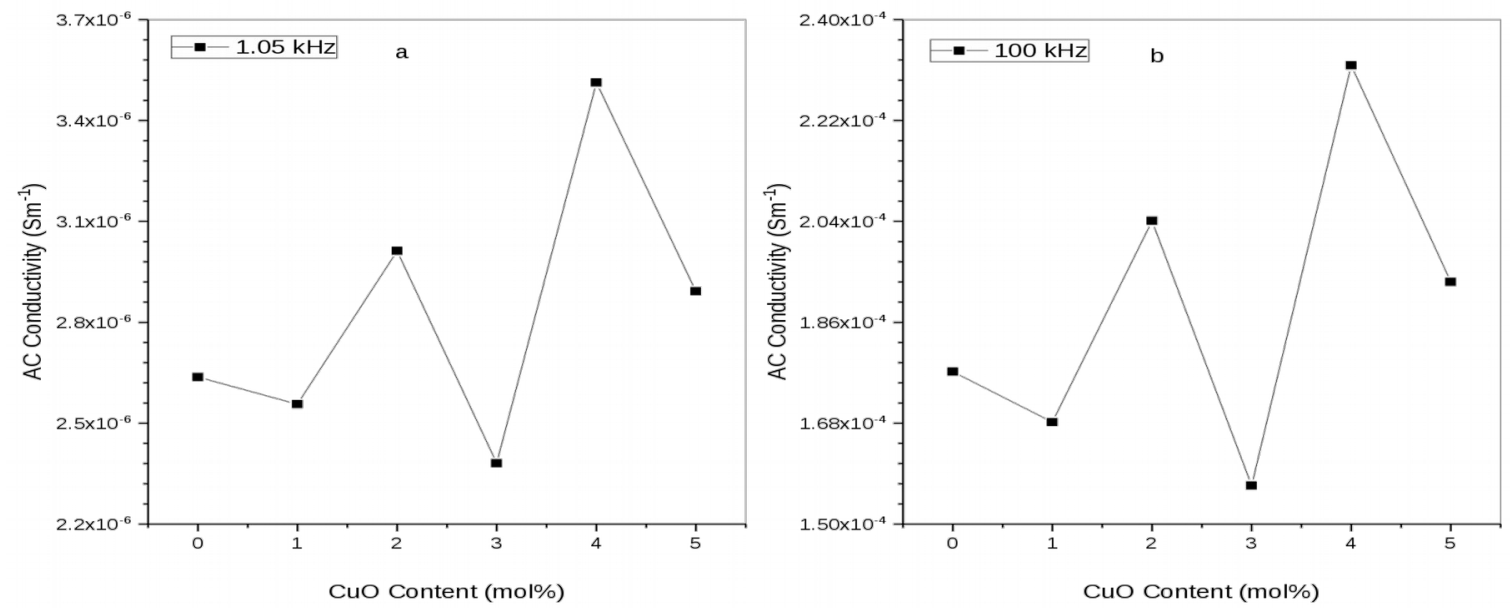

Figure 7: The change in AC conductivity with increasing $\mathrm{CuO}$, measured at $1.05 \mathrm{kHz}$ (a) and $100 \mathrm{kHz}(\mathrm{b})$. 
distance between copper ions $\left(\mathrm{r}_{\mathrm{Cu}}\right)$ [44]. Therefore, the addition of $\mathrm{CuO}$ causes an increase in the polaron transfer and enhancing the conductivity. Moreover, the reduction of the interionic distance of copper ions with increasing $\mathrm{CuO}$ content [7], makes the electron hopping to be easier to occur. On the other hand, ionic conduction is known to be effective in glasses containing mobile ions, e.g. sodium ions. The ionic conductivity is also affected by the number of mobile ions and their mobility. The presence of $\mathrm{Al}_{2} \mathrm{O}_{3}$ in the investigated glasses causes an increase in the molar volume which act to increase the mobility of sodium ions remaining their effective role in ionic conductivity. The appearance of $\mathrm{Cu}^{+}$ions by further increase of $\mathrm{Al}_{2} \mathrm{O}_{3}$ content creates crosslinks within the glass network and reduces the pathways suitable for free sodium ions migration. This makes the increase of conductivity is approximately slight with increasing $\mathrm{CuO}$ content.

\section{CONCLUSION:}

The dielectric parameters of CuO-doped phosphate glasses containing alumina have been investigated in the frequency range from 1.05 to100 kHz. According to the obtained results, it can be concluded that, the dielectric constant, dielectric loss and dissipation factor decrease with increasing frequency as a result of space charge and dipole polarization. The ac conductivity increases also in a slight and fluctuated manner with increasing frequency. The calculated s-factor values are found to be about 0.92 . The ac conductivity measurements confirm the coexistence of both electronic conductivity (due to the electron hopping from $\mathrm{Cu}^{+}$to $\mathrm{Cu}^{2+}$ ions) and ionic conductivity (due to the mobility of sodium ions).

\section{REFERENCES}

[1] R. H. Doremus, Glass Science, 2nd edn. ,Johh Wiley (1973).

[2] M. H. Shaaban, J. Electroceram., 28, (2012) 246.

[3] Lahcen Bih, Procedia, Engineering, 83, (2014) 371.
[4] Said Aqdim and Malika Ouchetto, Advances in Materials, Phys. and Chem., 3 (2013) 332.

[5] S.F. Khor, American J. Applied Sciences, 6 (2009) 1010.

[6] A. Chahine, Materials Chemistry and Physics, 84 (2004) 341.

[7] Y. H. Elbashar, Optik-International J. Light and Electron Optics, 127 (2016) 7041.

[8] K. A. Narula, R. Singh and S. Chandra, Bulletin of Materials Science, 23 (2000) 227.

[9] D. Cheng, "Field and Wave Electromagnetics", New York: Addison-Wesley, USA (1989).

[10] M. Barsoum, "Fundamentals of Ceramics", McGraw-Hill, New, York (1997).

[11] H. E. Atyia, Vacuum, 81 (2007) 590.

[12] A. Duran and J.M. Fernandez Navarro, Phys. Chem. Glasses, 26 (1985) 126.

[13] L. L. Hench and J. K. West, "Principles of Electronic Ceramics”, Wiley, New York, (1990).

[14] Banwarial S. K. Khosa, Ravender Tickoo, K. K. Bam-zai and P. N. Kotru, Materials Chem. and Phys., 83 (2004) 158.

[15] Mohamed M. El-Desoky, J. Phys. and Chem. Solids, 59 (1998) 1659.

[16] R. H. Chen, R. J. Wang, T. M Chen and C. S. Shern, J. Phys. Chem. Solids, 61 (2000) 519.

[17] J. Qiu, K. Miyauchi, N. Kawamoto and K. Hirao, Appl. Phys. Lett., 81 (2002) 394.

[18] P. Venkateswara Rao, T. Satyanarayana, M. Srinivasa Reddy, Y. Gandhi and N. Veeraiah, Physica (B), 403 (2008) 3751.

[19] V. Ravi Kumar, N. Veeraiah, S. Buddhudu and V. Jaya TyagaRaju, J. Phys. (III) France, 7 (1997) 951.

[20] A.A. Sattar and S.A. Rahman, Phys. Stat. Sol. (a), 200 (2003) 415.

[21] Maurya D. Kumar and J. Shripal, J. Phys. Chem. Solids, 66 (2005) 1614.

[22] S. Maity, D. Bhattacharya and S.K. Ray, J. Phys. D: Appl. Phys., 44 (2011) 095403.

[23] S. Bhardwaj, J. Pail and S. Chand, J. Mater. Sci., Mater. Electron., 25 (2014) 4568.

[24] M. A. White, "Physical Properties of Materials”; CRC Press, Boca Raton, FL, USA (2011). 
[25] M.D. Ingram, Physics and Chemistry of Glasses, 28 (1987) 215.

[26] L. Murawski, R.J. Barczyn'ski and D. Samatowicz, Solid State Ionics, 157 (2003) 293.

[27] Ilias Stavrakas, Open J. Applied Sciences, 2 (2012) 61.

[28] K. Jonscher, J. Materials Science, 13(1978) 553.

[29] A. Angell, Chemical Reviews, 90 (1990) 523.

[30] S. R. Elliott, Advances in Physics, 36 (1987) 135.

[31] W. K. Lee, J. F. Liu and A. S. Nowick, Physical Review Letters, 67 (1991) 1559.

[32] L. Murowski and R. J. Barczynski, J. NonCryst.Solids, 185 (1995) 84.

[33] L. Pavic, A. Moguš-Milankovic, P. Raghava Rao, A. Šantic, V. Ravi Kumar and N. Veeraiah, J. Alloys and Compounds, $\underline{604}$ (2014) 352.

[34] Chandra Babu, K. Naidu and W. Madhuri, Materials Chemistry and Physics, 181 (2016) 432.

[35] Ali M. Ibrahim, A. M. Badr, H. A. Elshaikh, A. G. Mostafa and Y. H. Elbashar, Silicon, 9 (2017) 1.

[36] Yahia H. Elbashar, Ali M. Badr, Haron A. Elshaikh, Ahmed G. Mostafa and Ali M. Ibrahim, Processing and Application of Ceramics, 10 [4] (2016) 277.

[37] Ali M. Ibrahim, Y. H. Elbashar, A. M. Badr, H. A. Elshaikh and A. G. Mostafa, J. Microwave Power and Electromagnetic Energy, 51 (2017) 1.

[38] P. Ramesh Babu, R. Vijay, P. SrinivasaRao, P. Suresh, N. Veeraiah and D. Krishna Rao, J. Non-cryst.Solids, 370 (2013) 21.

[39] Gnanaprakasm Little Flower, Maddireddy Srinivasa Reddy, Musugu Venkata Ramana Reddy and Nalluri Veeraiah, J. physics sciences, 62 (2007) 315.

[40] V. Saltas, J. Hazardous Materials, 142 (2007) 520.

[41] S.F. Khor, Z.A. Talib, H.A.A. Sidek, W.M. Daud and B.H. Ng, American J. Applied Sciences, 6 (2009) 1010.
[42] Consuelo Mugoni, J. Non-Cryst. Solids, 383 (2014) 137.

[43] B. Vijaya Kumar, Physica(B), 404 (2009) 3487.

[44] A. Šantić, C.W. Kim, D.E. Day and A. MogušMilanković, J. Non-Cryst. Solids, 356 (2010) 2699. 